\title{
PROPUESTA DE MODELO HOLÍSTICO PARA LA EVALUACIÓN INTEGRAL Y DE LOS APRENDIZAJES EN UNA ESCUELA TRANSFORMADORA
}

\author{
Holistic Model Proposal for the comprehensive evaluation \\ and learning in a Transformative School
}

Giovanni Marcelo lafrancesco Villegas*

lafrancesco, G. M. (2016). Propuesta de modelo holístico para la evaluación integral y de los aprendizajes en una escuela transformadora. Revista PACA, 8, 34-50

\section{Contexto}

La organización de esta propuesta evaluativa surge de la sistematización de una experiencia exitosa que inicia en el año 2004 en el Gimnasio Los Andes en Bogotá D.C., Colombia, cuando era su rector y se adoptó como Proyecto Educativo Institucional mi propuesta original de "Educación y Pedagogía Transformadora EEPT" con la que fundé el Liceo Cambridge, también en Bogotá D.C., Colombia en el año 1997 y del cual fui rector hasta el año 2001. En el Gimnasio Los Andes se implementó y consolidó desde el año 2003 al año 2009, mientras fui su rector, haciendo publicaciones periódicas en la Revista Educación y Pedagogía Gimandina de la cual fui su creador y director desde el año 2004 hasta el año 2009, con una producción de 9 revistas, cada una profundizando los aspectos relevantes del proceso.

\footnotetext{
*Doctor en Educación. Director Corporación Internacional Pedagogía y Escuela Transformadora CORIPET Miembro Fundador y de Número de la Academia Colombiana de Pedagogía y Educación ACOLPE.

Email:g_iafrancesco@yahoo.com
} 
Para el inicio de este proceso fueron claves los dos primeros números de la revista:

- Revista No 1 de noviembre del 2004, con 26 artículos publicados y en la cual se configura el PEI y el papel de la evaluación en el mismo, que inicia con (1) "La propuesta de Escuela Transformadora como Alternativa Pedagógica en el Gimnasio Los Andes" (Iafrancesco, G. 2004).

- Revista No. 2 de junio de 2005 (primer semestre), con 10 artículos publicados, de los cuales dos de ellos permiten el inicio de este trabajo: (2) "La evaluación Integral desde la perspectiva de una Escuela Transformadora" (lafrancesco, G. 2005) y (3) "Criterios y Conceptos para la evaluación del aprendizaje" (Iafrancesco, G y Díaz F. 2005).

A partir de estos trabajos se inicia el proceso de construcción conceptual y operacional estructural de la propuesta evaluativa, proponiendo nuevos conceptos de evaluación, construyendo un decálogo de principios que aportan a la orientación de los procesos evaluativos, formulando pertinentes objetivos a la evaluación según la propuesta de Escuela Transformadora planteada y de la creación del Modelo Pedagógico Holístico que permite desarrollarla e inspira sus características, procesos que se han venido publicando en diferentes revistas y en mis libros.

Estos son los conceptos, principios, objetivos y características claves para comprender la Propuesta de Modelo Holístico para la Evaluación Integral y del Aprendizaje del que trata este artículo para la Revista PACA y lo hago como docente - investigador amigo del Grupo de Investigación que soporta, con sus trabajos, esta revista:

1. Desde la perspectiva de mi propuesta de Educación, Escuela y Pedagogía Transformadora -EEPT-, considero que (4) "la evaluación es un proceso sistemático y permanente que comprende la búsqueda y obtención de información de diversas fuentes acerca de la calidad de la enseñanza y del aprendizaje, del desempeño, de los avances, del rendimiento, de los logros del educando y del educador; de la calidad de los procedimientos, métodos, técnicas y estrategias empleados por el educador y por el educando en los procesos de enseñanza-aprendizaje y de formación integral; de la organización y análisis de esta información a manera de 
diagnóstico y de su valoración objetiva; de la determinación de su importancia, coherencia y pertinencia, de conformidad con los objetivos de formación que se espera alcanzar; todo con el propósito de tomar las mejores decisiones que orienten el aprendizaje y canalizar los esfuerzos de la gestión educativa para asegurar el éxito de quien aprende y de quien enseña" (lafrancesco, G., 2004).

2. De acuerdo con lo expresado anteriormente, considero hoy, con otras palabras, pero con la misma idea, el mismo concepto y, desde el mismo contexto y referente, que (5) "la evaluación es un proceso que comprende: la búsqueda y obtención de información, el diagnóstico acerca de la realidad observada -individual y grupal-, la valoración en conformidad con las metas propuestas, la determinación de los factores que están incidiendo y la toma de decisiones que consecuentemente se derivan de dicho proceso, para asegurar el mejoramiento, el permanente progreso y el alcance del éxito" (Iafrancesco, G. 2012).

3. Desde la perspectiva de mi propuesta de Educación, Escuela y Pedagogía Transformadora -EEPT-, considero como (6) "principios fundamentales de la evaluación de los aprendizajes, los siguientes: Principio 1: La evaluación es parte integral, integrante e integradora del proceso global de la educación en todos sus niveles; Principio 2: La evaluación debe efectuarse de acuerdo con los objetivos educativos y formativos; Principio 3: La evaluación se aplica a todos los factores que de algún modo inciden en el proceso educativo; Principio 4: La evaluación es un medio, no un fin en sí misma; por lo tanto, también debe evaluarse; Principio 5: Dentro de la acción educativa y formativa, la evaluación constituye un proceso continuo de retroinformación, de retroalimentación y de mejoramiento; Principio 6: En la evaluación deben tenerse en cuenta las diferencias individuales; Principio 7: La evaluación carece de métodos, técnicas, procedimientos e instrumentos infalibles; Principio 8: La evaluación requiere la participación valorativa de diferentes personas; Principio 9: La evaluación requiere una gran variedad de estrategias para recoger, procesar, analizar y valorar la información; Principio 10: La evaluación no busca recompensar o castigar, sino investigar cómo mejorar el producto y el proceso de la formación y del aprendizaje" (Iafrancesco, G. 2011). 
4. Desde la perspectiva de mi propuesta de Educación, Escuela y Pedagogía Transformadora -EEPT-, son (7) "objetivos de la evaluación de los aprendizajes, cuatro áreas fundamentales: a) el área del dominio conceptual y procedimental; b) el área del dominio cognitivo, c) el área de formación humana y d) el área del comportamiento social ( lafrancesco, G. 2017), los cuales permiten asegurar el logro de los siguientes aprendizajes, respectivamente: (8) "a) Aprender a Saber (Competencias Académicas y Científicas); Aprender a Saber Hacer (Competencias Laborales, Ocupacionales, Técnicas y Tecnológicas); Aprender a Emprender (Competencias de Emprendimiento); b) Aprender a Pensar (Competencias Cognitivas) y Aprender a Aprender (Competencias Investigativas); c) Aprender a Ser (Competencias Antropológicas), Aprender a Sentir (Competencias Afectivas), Aprender a Actuar (Competencias Éticas y Morales) y Aprender a Vivir (Competencias Axiológicas y Espirituales); d) Aprender a Convivir (Competencias Sociales, Ciudadanas y de Liderazgo)" (Iafrancesco, G. 2011).

5. Desde la perspectiva de mi propuesta de Educación, Escuela y Pedagogía Transformadora -EEPT-, son (9) "características de la evaluación de los aprendizajes, las siguientes: o Estructurada y articulada. o Secuencial, continuada, progresiva y acumulativa. o Contextualizada y circunstancial. o Asistemática -condicionada al objetivo, al evento y al educando-. o Rediseñable, flexible y versátil. o Dinámica y permanente. o Integral, integrante e integradora del proceso holístico educativo y formativo. $o$ Diagnóstica, formativa y sumativa. o Valorativa, apreciativa, estimativa y correctiva. o Denotativa, connotativa y estructural. o Objetiva. o Técnica e instrumental. o Crítica constructiva. o Cooperativa. o Participativa. o Cualitativa y cuantitativa" (lafrancesco, G. 2017).

\section{Propuesta:}

Teniendo en cuenta el concepto de evaluación en una Escuela Transformadora, sus principios, los objetivos de la evaluación de los aprendizajes y sus características, desde este contexto anteriormente presentado, debemos asumir la evaluación integral y de los aprendizajes en los educandos en el aula de una Escuela Transformadora, teniendo en cuenta el desarrollo integral de los siguientes procesos y resultados: 
- Evaluación del proceso y del resultado del desarrollo académico de los educandos.

- Evaluación del proceso y del resultado del desarrollo intelectivo de los educandos.

- Evaluación del proceso y del resultado formativo en relación con el desarrollo humano en los educandos.

- Evaluación del proceso y del resultado del desarrollo social en los educandos.

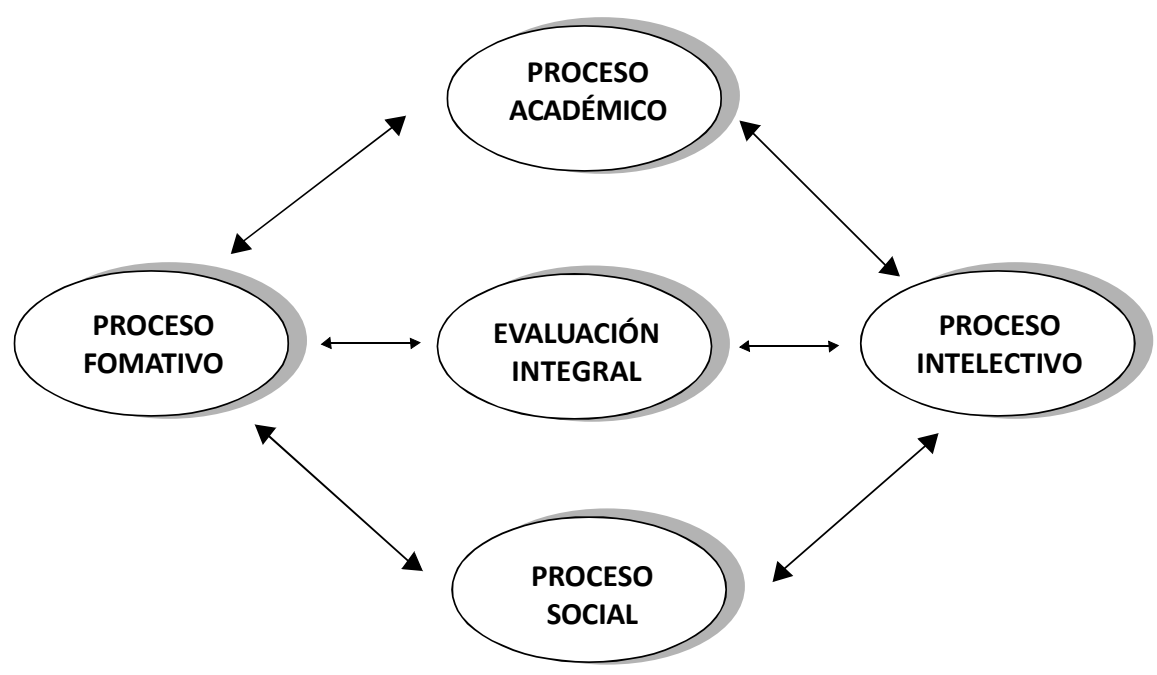

1. Evaluación del proceso y del resultado del desarrollo académico de los educandos:

En la evaluación de los procesos y productos del desarrollo académico de los educandos deben tenerse en cuenta los factores endógenos al aula que inciden en los aprendizajes: las actitudes, los conceptos, los procedimientos y las estrategias evaluativas; por tanto, es necesario realizar las siguientes evaluaciones:

- La evaluación actitudinal.

- La evaluación conceptual.

- La evaluación procedimental.

- La evaluación de la evaluación: meta-evaluación. 


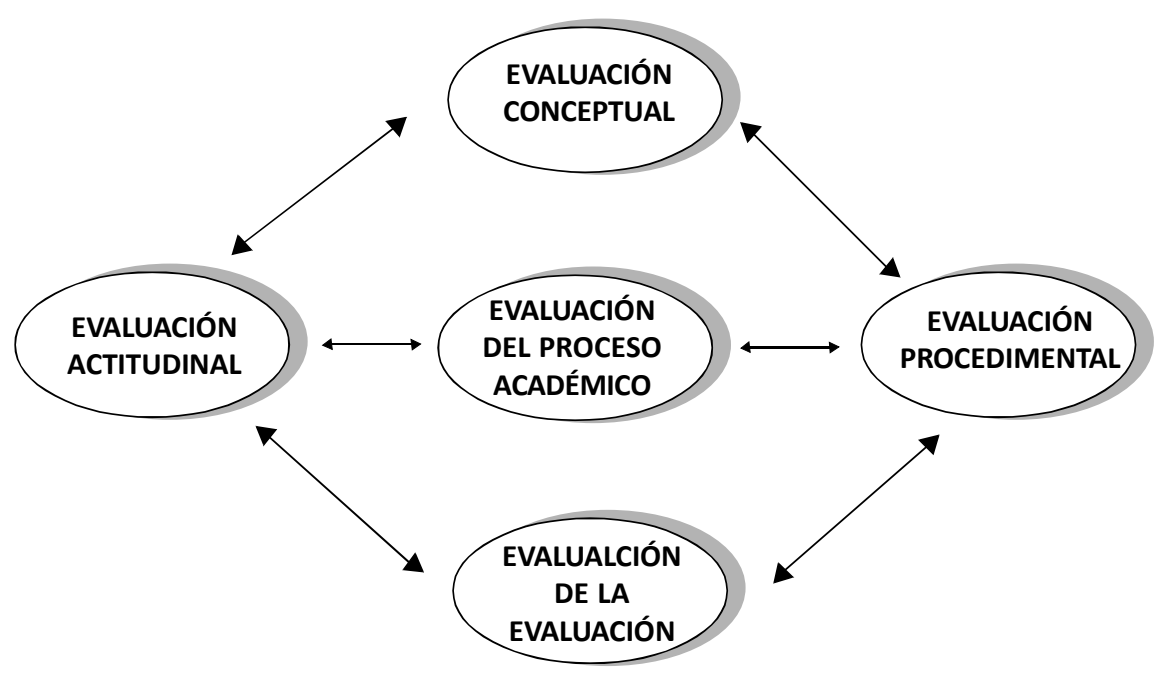

\subsection{Evaluación Actitudinal}

En la evaluación actitudinal se deben valorar, apreciar, estimar y juzgar las expectativas, el interés, la motivación, la atención, la pasión, la voluntad, la constancia, la persistencia y la responsabilidad que tienen los educandos frente al desarrollo de los trabajos en el aula y extra-aula, individuales y grupales, de acuerdo con los logros esperados (producto) y con los indicadores de logro establecidos para tal fin (proceso), en cada uno de los espacios formativos y académicos previstos por la institución educativa, en cada uno de los niveles escolares, de acuerdo con el plan de estudios y el diseño curricular institucional. Esta evaluación actitudinal se puede complementar con elementos de la evaluación de los comportamientos de los educandos.

Debe diseñarse un instrumento, según las características de organización institucional, para consignar la información relevante, tanto para la evaluación actitudinal y comportamental que permita evidenciar el proceso de desarrollo de competencias éticas, morales, axiológicas y de convivencia, mediante indicadores de logro y no logro y también, los resultados alcanzados en relación con los logros esperados previstos, según los niveles educativos y desde las áreas de formación establecidas. 


\subsection{Evaluación conceptual}

En la evaluación conceptual se deben valorar, apreciar, estimar y juzgar las nociones, los conceptos, las operaciones propuestas en las unidades didácticas, organizadas por núcleos temáticos, integrados en estructuras y redes conceptuales que conforman las asignaturas, integradas en las áreas que conforman el plan de estudios institucional, dentro del diseño curricular establecido, con los estándares curriculares de los aprendizajes definidos previamente, dentro de un enfoque claramente contextuado y unas condiciones que aseguran la construcción conceptual y los aprendizajes autónomo, significativo y colaborativo mediado. EI seguimiento debe hacerse desde los conocimientos adquiridos, los conceptos construidos, el manejo técnico de los implementos con que se trabaja en ellos, la seguridad en su uso, la calidad de los trabajos, el nivel de rendimiento.

Debe diseñarse un instrumento, según las características de organización institucional, para consignar la información relevante relacionada con la evaluación conceptual, el cual permita evidenciar el proceso de desarrollo mediante indicadores de logro y no logro y también, los resultados alcanzados en relación con los logros esperados previstos, según los niveles educativos y desde las áreas de formación establecidas.

\subsection{Evaluación procedimental}

En la evaluación procedimental se deben valorar, apreciar, estimar y juzgar la aplicación de los métodos, las técnicas, los procesos, los procedimientos, los protocolos y las estrategias de construcción conceptual y de aprendizaje, como también los hábitos, las habilidades y destrezas desarrolladas y expresarlos en desempeños, valorados estos desde los criterios de eficiencia, eficacia, efectividad y pertinencia.

Debe diseñarse un instrumento, según las características de organización institucional, para consignar la información relevante relacionada con la evaluación procedimental, el cual permita evidenciar el proceso de desarrollo mediante indicadores de logro y no logro, y también los resultados alcanzados en relación con los logros esperados previstos, según los niveles educativos y desde las áreas de formación establecidas. 


\subsection{Evaluación de la evaluación}

En la evaluación de la evaluación - meta-evaluación- se deben valorar, apreciar, estimar y juzgar los objetivos de las evaluaciones realizadas, los principios evaluativos tenidos en cuenta en ellas, las características de las evaluaciones implementadas, el enfoque de la evaluación utilizado (por normas o criterios), el tipo de evaluación implementado (diagnóstica, formativa, sumativa, intermedia, terminal, interna, externa, de procesos, de impacto, participativa, institucional, de programas y proyectos, autoevaluación, co-evaluación, hetero-evaluación), el tipo de modelo analítico o global usado como referente ( CIPP, de referentes específicos, focalizado y/o iluminativo), los procesos desde los que se organizan estas modalidades de evaluaciones, los instrumentos construidos, estructurados, diseñados y aplicados para realizar la recolección de la información para asumir la evaluación y los resultados alcanzados con su aplicación.

Debe diseñarse un instrumento, según las características de organización institucional, para consignar la información relevante relacionada con la evaluación de la evaluación -meta-evaluación-, que permita evidenciar el proceso de planeación, diseño, aplicación y valoración de los instrumentos de evaluación utilizados, el análisis de su coherencia y pertinencia y, las alternativas de mejoramiento si tiene posibilidades de cualificarlo o, la sistematización del instrumento por el éxito logrado al valorarlo como coherente y pertinente.

\section{Evaluación del proceso y del resultado del desarrollo intelectivo de los educandos}

En la evaluación de los procesos y productos del desarrollo intelectivo de los educandos deben tenerse en cuenta los factores cognitivos que inciden en los aprendizajes autónomo y significativo; por tanto, es necesario realizar las siguientes evaluaciones:

- Evaluación de las funciones cognitivas

- Evaluación de los procesos de pensamiento y las habilidades mentales

- Evaluación de las múltiples inteligencias

- Evaluación del potencial de aprendizaje 


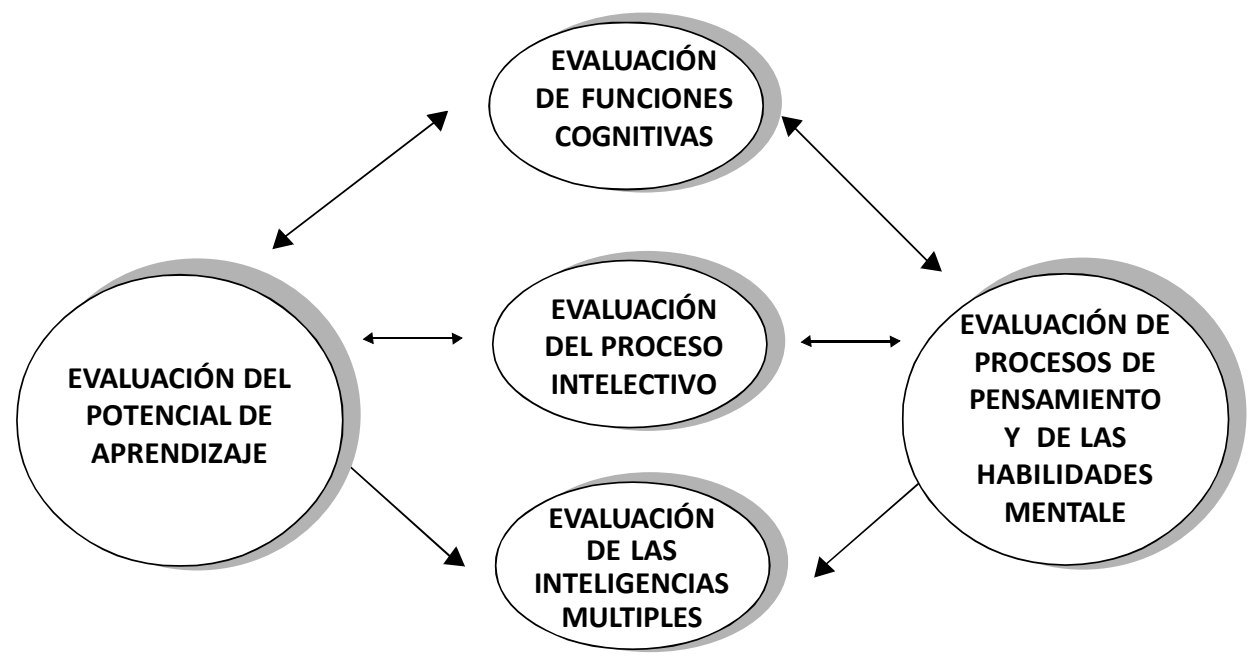

\subsection{Evaluación de las funciones cognitivas}

En la evaluación de las 26 funciones cognitivas se deben valorar, apreciar, estimar y juzgar en sus fases de input (antes de aprender), elaboración (mientras se aprende) y output (después de aprender), así:

En la fase de INPUT: 1. Percepción clara. 2. Exploración sistemática de situaciones de aprendizaje. 3. Habilidades lingüísticas a nivel de entrada. 4. Orientación espacial. 5. Orientación temporal. 6. Conservación, constancia y permanencia de objeto en la mente. 7. Organización de la información. 8. Precisión y exactitud en la recogida de la información.

En la fase de elaboración: 9. Percepción y definición de un problema. 10. Selección de información relevante. 11. Interiorización y representación mental. 12. Amplitud y flexibilidad mental. 13. Planificación de la conducta. 14. Organización y estructuración perceptiva. 15. Conducta comparativa. 16. Pensamiento hipotético. 17. Evidencia lógica. 18. Clasificación cognitiva.

En la fase de OUTPUT: 19. Comunicación explícita. 20. Proyección de relaciones virtuales. 21. Reglas verbales para comunicar la respuesta. 22. Elaboración y desinhibición en la comunicación de las respuestas. 23. Respuestas por ensayo error. 24. Precisión y exactitud en las respuestas 25. Transporte visual. 26. Control de las respuestas. 


\subsection{Evaluación de los procesos de pensamiento y las habilidades mentales}

En la evaluación de los procesos de pensamiento y de las habilidades mentales se deben valorar, apreciar, estimar y juzgar las competencias cognitivas básicas, así:

Para evaluar las competencias interpretativas se deben valorar, apreciar, estimar y juzgar el proceso de mecanización-memoria mecánica-mediante la verificación de la realización de las siguientes tareas por parte del educando: recoger, procesar, organizar y almacenar información, retenerla, recordarla y evocarla y; el proceso de concreción -pensamiento concretomediante la verificación de la realización de las siguientes tareas por parte del educando: Partir de las experiencias y las vivencias para elaborar imágenes mentales y organizar ideas, elaborar conceptos y tomar postura crítica frente a ellos. Esto implica observar, percibir, describir, comparar, clasificar, agrupar, sistematizar, delimitar, definir, pre-conceptuar, criticar e interpretar: Primer nivel de competencias cognitivas básicas.

Para evaluar las competencias argumentativas se deben valorar, apreciar, estimar y juzgar el proceso de configuración -memoria configurativamediante la verificación de la realización de las siguientes tareas por parte del educando: identificar elementos de una estructura conceptual, definir las funciones de estos elementos, establecer relaciones entre los elementos y con el todo dependiendo de las funciones de los mismos, organizar la estructura conceptual, encontrarle el sentido y el significado, y el proceso de abstracción -pensamiento abstracto- mediante la verificación de la realización de las siguientes tareas por parte del educando: ir del todo a las partes y de las partes al todo, descomponer y recomponer, globalizar y particularizar, generalizar y especificar, deducir e inducir, analizar y sintetizar, concluir, explicar, sustentar y argumentar: Segundo nivel de competencias cognitivas básicas.

Para evaluar las competencias propositivas se deben valorar, apreciar, estimar y juzgar el proceso lógico-memoria lógica-mediante la verificación de la realización de las siguientes tareas por parte del educando: establecer relaciones causa-efecto, interpretar y argumentar el proceso implícito en esta relación causa-efecto, describir, delimitar, definir, plantear 
y formular problemas, formular hipótesis, seleccionar y validar variables, predecir resultados, prever conclusiones, proponer alternativas de solución provisionales o definitivas, y el proceso de formalización -pensamiento formal- mediante la verificación de la realización de las siguientes tareas por parte del educando: experimentar la alternativa de solución propuesta; verificar, comprobar y demostrar que ésta es viable, lógica y pertinente; justificar la necesidad de aplicar esta estrategia, aplicarla y con ella evidenciar que la estrategia es exitosa, de forma provisional o definitiva; hacer adecuaciones, transferencias y transformaciones; ingeniar, crear, innovar e inventar, para de forma definitiva resolver los problemas o producir nuevo saber: Tercer nivel de competencias cognitivas básicas.

\subsection{Evaluación de las múltiples inteligencias}

En la evaluación de las múltiples inteligencias se deben valorar, apreciar, estimar y juzgar: las actitudes, las aptitudes, los hábitos, las habilidades, las destrezas, las competencias y los desempeños propios de los talentos que evidencian alguna de las múltiples inteligencias propuestas por $\mathrm{H}$. Gardner, con los instrumentos apropiados para ello; estas son: lingüística, lógico-matemática, naturalística, espacial, musical, corporal-motriz (kinestésica), emocional (interpersonal) y ético-moral (intrapersonal).

\subsection{Evaluación del potencial de aprendizaje}

En la Evaluación del potencial de aprendizaje se deben valorar, apreciar, estimar y juzgar, mediante el modelo de evaluación dinámica del potencial de aprendizaje: a) las operaciones intelectivas: identificación, diferenciación, representación mental, transformación mental, comparación, clasificación, codificación-decodificación, proyección de relaciones virtuales, análisis y síntesis, inferencia lógica, razonamiento analógico, razonamiento hipotético, razonamiento transitivo, razonamiento silogístico, razonamiento divergente y razonamiento lógico; b) el mapa cognitivo y el acto mental para detectar las funciones cognitivas deficientes, el funcionamiento de las operaciones intelectivas, el vocabulario, las nociones, los conceptos, la capacidad cognoscitiva, las habilidades mentales, los hábitos de estudio, la motivación, el interés, las expectativas, los procesos de asimilación, acomodación y adaptación activa y la construcción, aplicación y transferencia de conocimiento. 


\section{Evaluación del proceso y del resultado formativo en relación con el desarrollo humano en los educandos}

En la evaluación de los procesos y productos del desarrollo humano de los educandos deben tenerse en cuenta:

- La evaluación antropológica

- La evaluación axiológica y espiritual

- La evaluación ético-moral

- La evaluación bio-psico-social, afectiva y estética

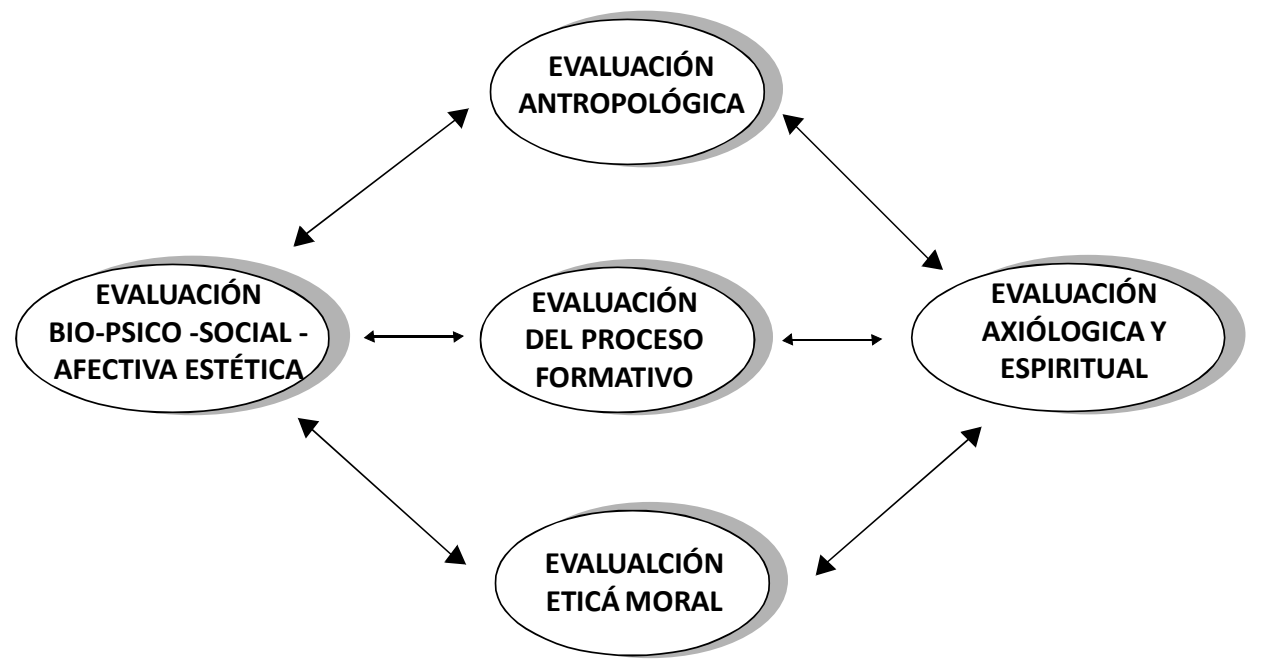

\subsection{Evaluación antropológica}

En la evaluación antropológica se deben valorar, apreciar, estimar y juzgar el desarrollo de la singularidad (originalidad, creatividad, autoreconocimiento, criticidad, autocontrol), la autonomía (la libertad de opción, elección y decisión responsable, proyecto de vida, voluntad, criterios), la apertura (disponibilidad, generosidad, disposición asertiva, comprensión, simpatía, sana convivencia) y la trascendencia de los educandos en su forma de ser, sentir, pensar y actuar en el aula (superación personal, dominio personal, auto-valoración, mejoramiento continuo, religiosidad). 


\subsection{Evaluación axiológica y espiritual}

En la evaluación axiológica y espiritual se deben valorar, apreciar, estimar y juzgar: a) los valores humanos, sociales, culturales y ecológicos, especialmente: el respeto, la responsabilidad, el compromiso, y b) los valores espirituales: la prudencia, la discreción, la paciencia, la humildad, la firmeza, la constancia, la cordura, la mesura, entre otros).

\subsection{Evaluación ética y moral}

En la evaluación ética y moral se deben valorar, apreciar, estimar y juzgar: los principios y valores éticos de la integridad y las actitudes y comportamientos morales de la responsabilidad; entre ellos: la honestidad, el respeto, la veracidad, la lealtad, la gratitud, el honor, la moderación, la fidelidad, la disciplina personal, el liderazgo positivo.

\subsection{Evaluación bio - psico - social, afectiva y estética}

En la evaluación bio-psico-social, afectiva y estética se deben valorar, apreciar, estimar y juzgar: a) en el desarrollo bio-psico-social: el crecimiento físico, social, emocional y mental, de forma psicológicamente integrada (psicología evolutiva y del desarrollo) con los criterios de madurez esperados según el desarrollo previsto, tanto de forma individual como grupal; las preferencias y desagrados producto de las aspiraciones personales de acuerdo con los esquemas sociales, culturales y familiares; b) en el desarrollo de la afectividad: la sintonía, la empatía, la simpatía, la amabilidad, la credibilidad, la confianza, la comprensión, la seguridad, la independencia, y el manejo apropiado de la alegría, la tristeza, el miedo, el duelo, el dolor y la rabia; c) en el desarrollo estético: la armonía, el equilibro, el arte, la calidad de las expresiones, el cultivo de la bondad, la verdad, la honestidad, la belleza, el orden, la higiene, el aseo.

\section{Evaluación del proceso y del resultado formativo en relación con el desarrollo social en los educandos}

En la evaluación de los procesos y productos del desarrollo social de los educandos deben tenerse en cuenta: 
- La evaluación de la cultura ciudadana

- La evaluación del liderazgo

- La evaluación de las relaciones interpersonales

- La evaluación del compromiso social

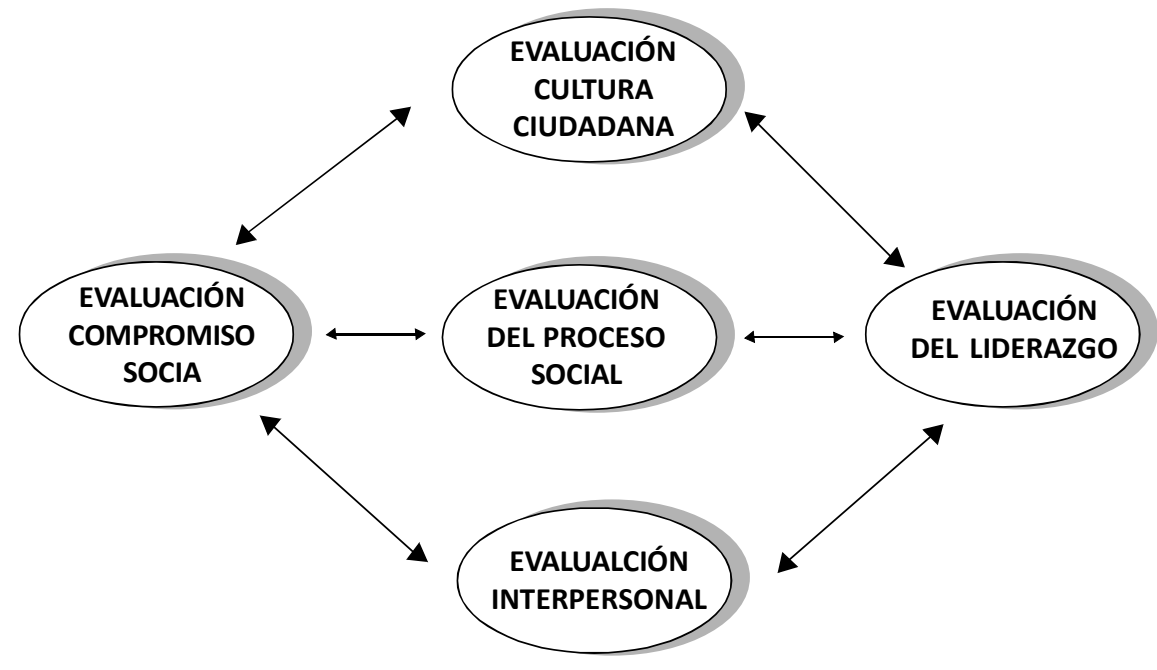

\subsection{Evaluación de la cultura ciudadana}

En la evaluación de la cultura ciudadana en los educandos se deben valorar, apreciar, estimar y juzgar: todos los valores éticos y morales mínimos que facilitan la convivencia pacífica, las actitudes y comportamientos que se desprenden de los propósitos, principios, valores comunitarios, descritos en el horizonte institucional previsto en los Proyectos Educativos Institucionales, en sus manuales de convivencia y en sus reglamentos escolares, organizados, de forma pertinente, para dar respuesta a las necesidades locales, municipales, regionales y nacionales, según los objetivos de los programas de desarrollo de la cultura ciudadana de cada país, de cada región, de cada municipio, de cala localidad, de cada institución educativa.

\subsection{Evaluación del liderazgo}

En la evaluación del liderazgo de los educandos, se deben valorar, apreciar, 
estimar y juzgar, desde el liderazgo positivo y responsable: La pro-actividad, la autogestión, el protagonismo, el compromiso, la laboriosidad, la productividad, el emprendimiento, el ingenio, la creatividad, la innovación, la integridad y la disposición asertiva para trabajo en equipo y para resolver problemas.

\subsection{Evaluación de las relaciones interpersonales}

En la evaluación de las relaciones interpersonales en los educandos se deben valorar, apreciar, estimar y juzgar: la inteligencia emocional, la capacidad de controlar las emociones, los afectos y los sentimientos extremos que llevan a la apatía y la antipatía, desarrollando buenos sentimientos expresados en la simpatía y la empatía, en la amistad honesta y responsable; la capacidad de prever y evitar conflictos y, cuando estos se dan, la capacidad de negociar, conciliar, concertar y mediar para que estos se disipen y se resuelvan.

\subsection{Evaluación del compromiso social}

En la evaluación del compromiso social en los educandos se deben valorar, apreciar, estimar y juzgar: la fraternidad, el servicio, el compromiso, la solidaridad, la justicia, la equidad, la tolerancia, la asertividad, la empatía, la caridad, el altruismo como valores y actitudes que aseguran excelentes comportamientos humanos frente a los problemas que tienen las personas con privaciones sociales, económicas, culturales, físicas, de salud, de nutrición, afectivas, que las hacen fácilmente vulnerables y que son discriminadas por quienes carecen, precisamente de inteligencia emocional y de compromiso social.

\section{Conclusión}

De forma inductiva y estructurada, con los elementos de la evaluación académica, intelectiva, formativa y social, la función que cumplen cada una de estas evaluaciones en el desarrollo de los educandos, con sus relaciones entre sí y con el todo y con el sentido que da formar en el ser (competencias antropológicas), en el sentir (competencias afectivas), en el actuar (competencias éticas y morales), en el vivir (competencias axiológicas y espirituales), en el convivir (competencias ciudadanas), en 
el saber (competencias académicas y científicas), en el saber hacer (competencias laborales y ocupacionales), en el pensar (competencias cognitivas), en el aprender (competencias investigativas y tecnológicas) y en el emprender (competencias de liderazgo y emprendimiento), y contextualizado en el Modelo Pedagógico Holístico Transformador y en el Modelo Curricular holístico propio de la propuesta de Educación, Escuela y Pedagogía Transformadora -EEPT, podemos, de forma muy sintética, presentar el Modelo Evaluativo Holístico que nos permite valorar, apreciar, estimar y juzgar, con miras al mejoramiento continuo, el proceso integral de desarrollo que demandan los aprendizajes del Siglo XXI.

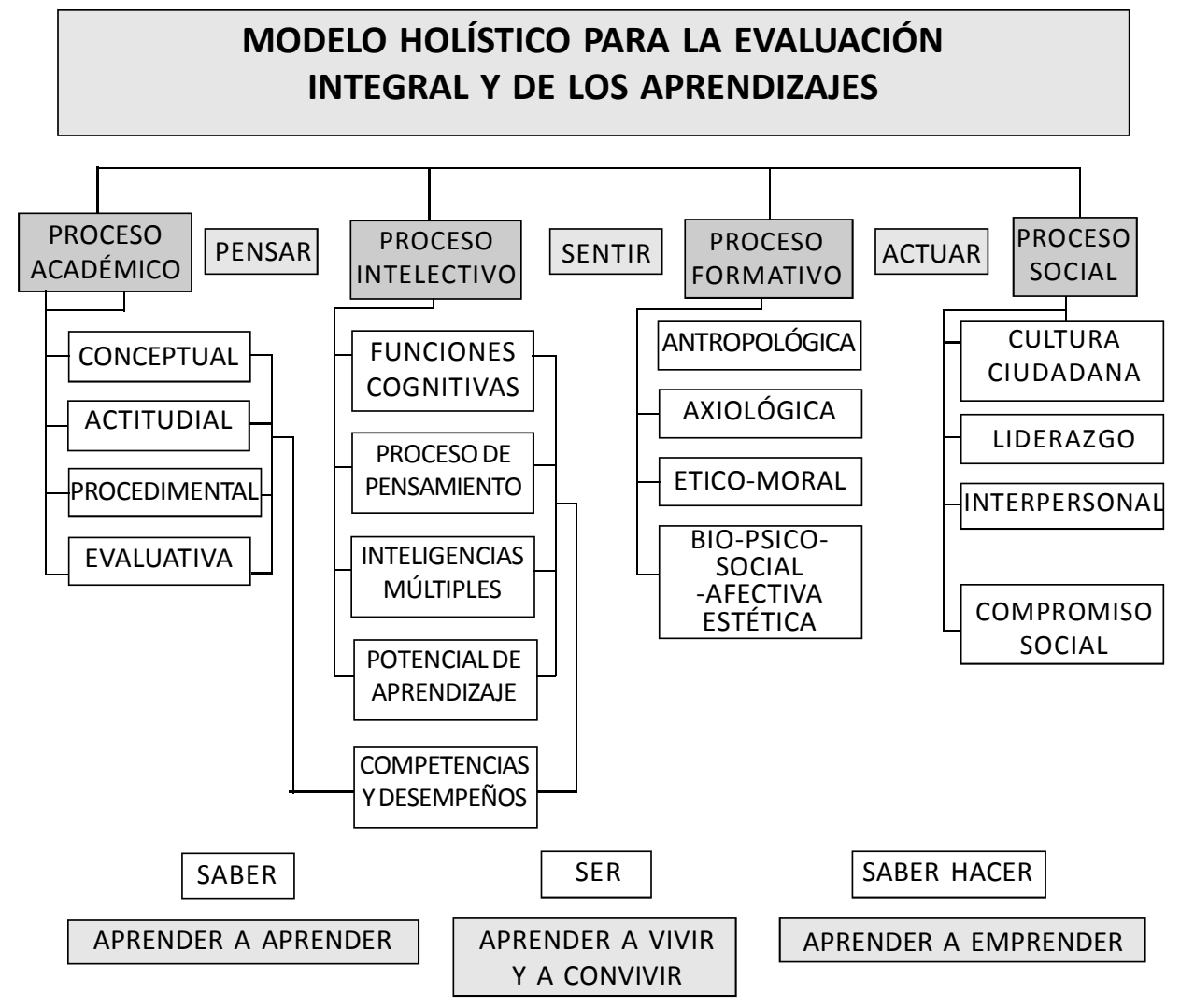




\section{Bibliografía}

1. Iafrancesco, Giovanni. La propuesta de Escuela Transformadora:

Alternativa Pedagógica en el Gimnasio Los Andes. Revista Educación y Pedagogía Gimandina, Año 1, No. 1 (Nov), Páginas 4 a 10, Gimnasio Los Andes, Bogotá, Colombia, 2004.

2. Iafrancesco, Giovanni. La evaluación integral desde la perspectiva de una Escuela Transformadora. Revista Educación y Pedagogía Gimandina, Año 2, No 2 (Junio), Páginas 41 a 44, Gimnasio Los Andes, Bogotá, Colombia, 2005.

3. Iafrancesco, G. y Díaz F. Criterios y conceptos para la evaluación del aprendizaje. Revista Educación y Pedagogía Gimandina, Año 2, No 2 (Junio), Páginas 45 a 48, Gimnasio Los Andes, Bogotá, Colombia, 2005.

4. Iafrancesco, Giovanni. La evaluación integral y del aprendizaje: Fundamentos y estrategias. Serie Escuela Transformadora. Cooperativa Editorial Magisterio. Página 29, Bogotá, Colombia, 2004.

5. Iafrancesco, Giovanni. La evaluación en el aula de una Escuela Transformadora. Colección Educación, Escuela y Pedagogía Transformadora. Coripet Editorial, Página 31. Bogotá, Colombia, 2012.

6. Iafrancesco, Giovanni. Modelo Pedagógico Holístico Transformador. Colección Educación, Escuela y Pedagogía Transformadora. Coripet Editorial, Página 240, 2a Edición, Bogotá, Colombia, 2015.

7. Iafrancesco, Giovanni. La Evaluación en el aula de una Escuela Transformadora. Colección Educación, Escuela y Pedagogía Transformadora. Coripet Editorial, página 39. Bogotá, Colombia, 2012.

8. Iafrancesco, Giovanni. Modelo Pedagógico Holístico Transformador. Colección Educación, Escuela y Pedagogía Transformadora. Coripet Editorial, Página 18. Bogotá, Colombia, 2011.

9. Iafrancesco, Giovanni. La Evaluación en el aula de una Escuela Transformadora. Colección Educación, Escuela y Pedagogía Transformadora. Coripet Editorial, páginas 67 y 68, 2a Edición. Bogotá, Colombia, 2017. 